\title{
Development of an integrated knowledge management and quality management model for small and medium sized companies in Trinidad and Tobago
}

Sandra Bissoon-Maharaj, Process Engineering Program, University of Trinidad and Tobago, West Indies, sandra.maharaj@utt.edu.tt

Rean Maharaj, Process Engineering Program, University of Trinidad and Tobago, West Indies, rean.maharaj@utt.edu.tt

\begin{abstract}
There appears to exist limited research regarding the integration of Knowledge Management (KM) and International Organization for Standardization (ISO)'s ISO9001 Quality Management Systems (QMS) for Small and Medium Sized Enterprises (SMEs), for Trinidad and Tobago (TT) and the Caribbean Region. TT has over 16,000 SMEs and approximately 10,000 micro enterprises, representing over $70 \%$ of all registered businesses, that employs over 50\% of the workforce. SMEs spark competition, create jobs, as well as promote innovation and knowledge transfer, thus are the engine of economic growth. SMEs in TT need to develop KM practices to compete regionally and globally, especially with the advent of the COVID-19 pandemic, which has triggered the deepest economic recession worldwide. Existing integrated KM models in other jurisdictions cannot be adopted in TT as KM is a culturally sensitive platform that needs to be customized to its applied environment. Results of a survey identified the Critical Success Factors (CSFs) for both Quality Management (QM) and KM required for the successful implementation of a Knowledge Management System (KMS). Data obtained showed that although the SMEs in TT demonstrated insignificant KM maturity, there is KM readiness, due to the existence of QMSs, significant information systems, human resource support, technical infrastructure, and senior management commitment. A five phase KM/QM integration model for SMEs in TT is proposed. Managers of SMEs and other similar operations may apply the findings of this study to develop strategies to integrate QM and KM to improve business results.
\end{abstract}

Keywords: Small and medium-sized enterprises, quality management, quality management system, knowledge management in Trinidad and Tobago (TT), knowledge management system, critical success factors.

\section{Introduction}

Trinidad and Tobago (TT) is the most industrialized island of the English-speaking Caribbean and the uniqueness of its diverse culture and social make-up sets it apart from all the other islands. The primary driver of TT's economy have been hydrocarbons and TT remains the largest oil and gas producer country in the Caribbean region and one of the largest methanol and ammonia producing countries in the world, contributing approximately 35\% to the island's Gross Domestic Product (GDP) (The Government of Trinidad and Tobago, 2021a). The energy and petroleum sector has 
faced economic headwinds as oil production is steadily decreasing, international commodity prices are falling with increasing competition worldwide. To illustrate this point, crude oil prices "averaged 107.19 MBBL/D from 1994 until 2019, reaching an all-time high of $156 \mathrm{MBBL} / \mathrm{D}$ in March of 2005 and a record low of 51MBBL/D in March of 2019" (Ramkissoon et al., 2020, p. 3972). As documented by Trinidad and Tobago Draft National Development Strategy, Vision 2030 (The Government of Trinidad and Tobago, 2021c) policy document, TT has embarked on an economic diversification pathway away from energy-based industries, developing innovative methods to help boost the economy and position TT to compete in revenue generation activities outside the energy-based sector. There are over 16,000 Small and Medium-sized Enterprises (SMEs) and approximately 10,000 micro enterprises in TT, together representing over 70\% of all registered businesses, and employing over $50 \%$ of the (The Government of Trinidad and Tobago, 2021b). These SMEs and micro enterprises are largely from the manufacturing sector, outside of the oil and gas sector, highlighting the importance of SMEs to the economic development of TT. According to The World Bank (2020) advent of the COVID-19 pandemic can cause the greatest decline in economic globally. Apart from the adverse health effects, economic activity is severely crippled, and unemployment is skyrocketing. The policies that are implemented now to guide countries towards recovery will redefine the economic and social outlook for the next 100 years. Emerging economies such as TT now have the opportunity to re-engineer and reorient operations to achieve competitiveness, sustainability, inclusiveness and resilience (Organization for Economic Co-operation \& Development, 2021).

Studies conducted by Nonaka (1994) and Teece (1998) demonstrated that knowledge and its quality are imperative for survival and growth in the current business environment and that Knowledge Management (KM) can enhance value creation in organizational processes, thus, support competitiveness. According to Koenig (2018), KM is the process of capturing, distributing and effectively using knowledge. As explained by Carvalho et al. (2016), both KM and Quality Management (QM) focus on people, process, and technology and share the objective of improving the performance of organizations; KM providing for QM the tools and techniques required for continual improvement. According to Bissoon-Maharaj and Pun (2010), it is inevitable that SMEs in TT will need to adopt KM practices to compete regionally and globally. TT boasts both a stable economy and political environment and small businesses are important for any national economy and knowledge is vital to their success (Choo et al., 2007; Desouza \& Awazu, 2006). SMEs have been identified to be drivers of economic growth in any society, as they generate jobs and encourage innovation and competition (Rothwell \& Zegveld, 1983). Improved knowledge quality helps companies to improve work performance, develop innovative and useful products and services, lower costs, and increase sales; it intensifies problem solving capabilities, increases process efficiency, and improves performance (Lee et al., 2008). According to Harris (2020), there is an urgent need for a shift in government policies to specifically promote the development and growth of the local SMEs through a package of incentives within the reach of these enterprises. Therefore, the objective of this study is to identify the relevant Critical Success Factors (CSFs) for integrating KM practices with Quality Management System (QMS) practices in SMEs in TT and to develop an indigenous KM and QM integration model relevant for SMEs in TT.

The paper is organized as follows. A review of the literature will be conducted to identify possible CSFs required for KM/QM integration. A Survey Instrument will be developed and utilized, guided by the CSFs identified, to provide a statistical snapshot to determine the relevant CSFs for KM and QM integration in SMEs in TT. The survey will also gauge the extent of KM readiness 
of these SMEs. These inputs will be required to develop a KM/QM integration model indigenous to TT. This model will provide the framework to be used by SMEs and other similar operations in TT to improve business results.

\section{Literature Review}

According to Karimzadegan et al. (2011), within recent times, KM has gained attention as a leading management strategy that can improve the effectiveness of organizations in an affordable manner. As a result, KM models are being developed and communicated to assist businesses in KM implementation. According to Bissoon-Maharaj and Pun (2010), SMEs that already have a QMS in place will find it beneficial in implementing a KMS. Kohl et al. (2015), further identified that "SMEs seem not to have disadvantages regarding the implementation of KM because of their size or industry, but rather because they need to take strategic decisions to implement such solutions and have difficulties in doing so" (p. 74). This is plausible as the primary objectives of QM and KM are the same, with both sharing the goal to creat business knowledge to improve a firm's performance (Linderman et al., 2004). Both KM and QM encourage the participation of people and aa focus on continuous improvement (Carvalho et al., 2016). A fundamental shortfall of the traditional QMS however is that it does not provide sufficient KM and opportunities to compete in the current dynamic industrial environment (Garstenauer et al., 2014). Garstenauer et al. (2014) also identified that improved performance in operations and systems are achieved by integrating KM and QM to form an enhanced QMS. Their research demonstrated that companies that implement $\mathrm{KM} / \mathrm{QM}$ practices report improvements in product quality and overall business performance (Garstenauer et al., 2014).

Work done by Lin and $\mathrm{Wu}$ (2005) as well as Lari (2002) emphasized the usefulness of International Organization for Standardization (ISO) 9000 for creating the experiences which help build organizational memory, with ISO documentation helping to safeguard those memories for future employees. According to Bissoon-Maharaj and Pun (2010), since ISO9000 QMS has been implemented by SMEs globally and has commonalities with KMS, facilitating KM practices through ISO9000 QMS for SMEs is expected and will lead to improved competitiveness. BissoonMaharaj and Pun (2010) also proposed a model which can assist with quality-related knowledge gathering and sharing and provides a conceptual structure for a quality assurance information system within companies. The identification and facilitation of CSFs will contribute to the degree of success or failure of a KM initiative for organizations considering transforming themselves into knowledge-based enterprises. Bissoon-Maharaj and Pun (2010) summarized CSFs for QMS as follows: senior executive commitment, resources and infrastructure (culture, information technology, human resources, organizational culture), knowledge related processes (creation, storage, distribution, application, managerial support), measurement and reward. Tan and Hung (2006) developed a KM introductory model for Taiwan which identified the following CSFs for KM implementation: knowledge management system planning (commitment and support, strategy, motivation), infrastructure building (information technology, human resource, organization structure, culture), knowledge processes implementation (creation, storage, distribution, application), measurement and improvement (measurement, gap analysis, reward) demonstrating that the CSFs for QMS and KM implementation are very similar. The identification of CSFs for KM implementation in developing Arabian countries was conducted by Rincon and Orero (2004) and their findings were consistent with those obtained by Bissoon-Maharaj and Pun 
(2010) as well as Tan and Hung (2006). They noted that the CSFs identified for implementing KM in developing countries include strategic planning, top management commitment as well as support from managers, information systems building by information systems managers to catalyze core business activities, designing, and developing KM and integrating with legacy systems with data cleansing, management of user expectations through clear communication plans and removal of borders between business functions. They also indicated that trust levels must be kept high, to allow knowledge to flow.

Successful strategies for implementing an integrated KM/QM Model in other jurisdictions cannot be simply adopted for SMEs in TT. Bissoon-Maharaj and Pun (2010) identified that the practice of KM in SMEs differ from that of large organizations because of their specific characteristics e.g., management structure, markets, systems, culture, and this sets them apart from larger organizations. Mazzarol (2014) has indicated that because of the structure of SMEs the bureaucracy of levels of authority seen in larger companies is eliminated, since the owner is more closely involved in the decision-making and day-to-day activities; which allows for greater flexibility in strategic planning and gradual and sometimes even radical technological innovation changes. According to Rincon and Orero (2004), KM is based on structure and people and culture will impact significantly; KM has to be tailored to the business climate. They further suggest that in-cooperating cultural ideas in management style would be an asset to organizations. The development of a unique and innovative approach is a key factor in designing a successful KMS (Barnes \& Milton, 2014). Research by Bissoon-Maharaj and Pun (2010) showed that a significant number of the SMEs in TT already have a QMS in place, putting them in an advantageous position to integrate a KMS. They hypothesized that ISO9000 certified SMEs in TT can apply the KM Integration Model and guidelines to enhance their quality initiative, helping to shift the focus toward a learning organization, with focus on customer relationship management and product innovation. They also suggested that a better understanding of CSFs for implementing KM in SMEs is needed in TT and showed the relationship between KM and QM. Although several studies have been conducted regarding the integration of KM and ISO9001 QMS for SMEs (Bissoon-Maharaj \& Pun, 2010; Garstenauer et al., 2014; Ribiere \& Khorramshahgol, 2004), research regarding its implementation for the Caribbean Region and TT and in particular the CSFs indigenous to the region, is limited. The current literature on KM assumes organizations to be large, global, and highly influenced by Western business structures and standards with complicated information technology (Lim \& Klobas, 2000). This information gap presents a significant hurdle towards implementing an integrated KM/QM Model in SMEs for TT and other regional enterprises.

\section{Methodology}

The flow chart shown in Figure 1 below describes the research methodology used in this study. The methodology utilized in this paper is consistent with other research (Bissoon-Maharaj \& Pun, 2010; Garstenauer et al., 2014; Ribiere \& Khorramshahgol, 2004). This methodology basically entails the development of a survey to be used to identify the CSFs for KM/QM integration in SMEs in TT. 


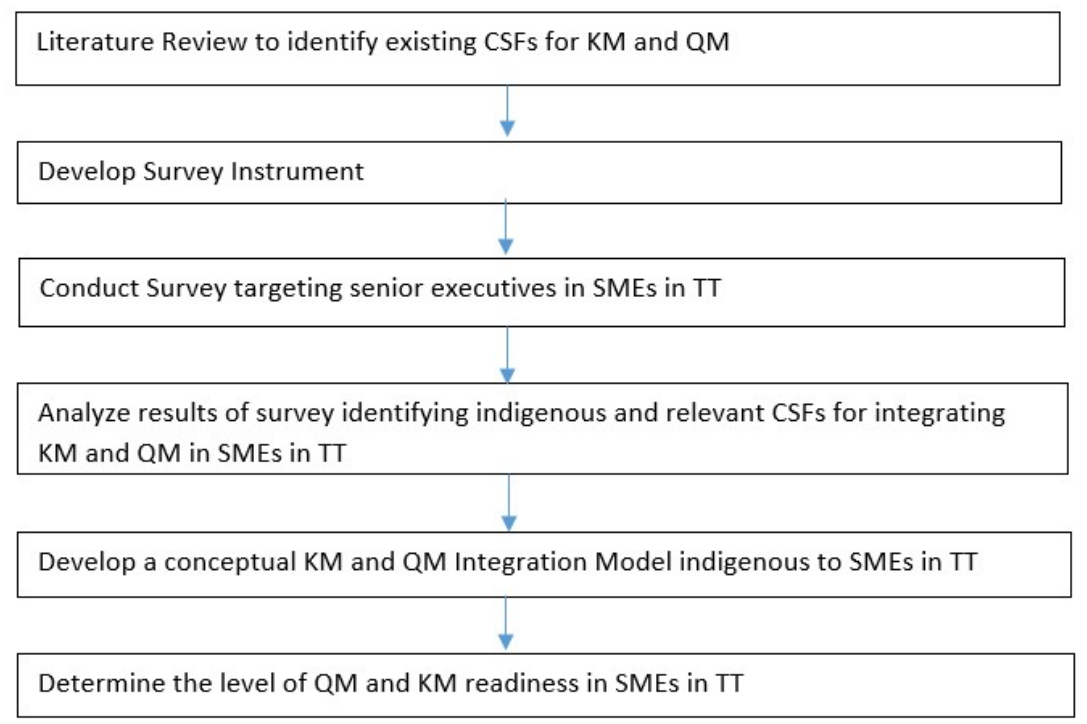

Figure 1. Methodology Flow Chart

Through Literature Review the relationship between KM and QM was explored and existing CSFs for KM and QM integration identified. These findings were detailed in the Literature Review section of this paper and used to assist in designing a Survey Instrument (see Appendix 1) to help identify the CSFs for KM/QM integration in SMEs in TT, as well as, to determine the extent of KM readiness in SMEs in TT. There were two parts (i \& ii) to each of the twenty-one questions in the survey instrument. Part (i) of each question was developed to assist in determining the extent of KM/QM readiness of SMEs in TT and part (ii) helped to determine the CSFs for KM/QM implementation in SMEs in TT.

The survey was conducted over a period of three months from July to September, 2020, targeting Senior Executives/Consultants of SMEs in the manufacturing and service industries in TT. There were $11 \mathrm{SME}$ responses to the survey with the answers to the questions showing a great extent of consistency. Because a statistical snapshot was required, 11 SME responses were deemed sufficient, however, in future studies this base will be widened to validate the model and findings. The responses to the survey were tabulated analyzed and graphically represented. The results obtained from the survey were used to develop a KM/QM integration model (Figure 4) for SMEs in TT, and to determine their level of KM/QM readiness.

\section{Results and Discussion}

\section{CSFs and the extent of readiness of SMEs in TT}

The primary objective of this study was to develop an integrated KM and QM model indigenous to TT. The key step for the development of the appropriate model involved the identification of the relevant CSFs for KM/QM integration in SMEs in TT. A pool of possible CSFs was obtained from studies in other jurisdictions via literature review and formed the basis of the Survey Instrument (Appendix 1) to be used to determine the relevant CSFs for TT. The overall procedure was consistent with protocol proposed by Bissoon-Maharaj and Pun (2010) consistent with other researchers (Garstenauer et al., 2014; Ribiere \& Khorramshahgol, 2004). With respect to the survey developed, it was validated to ensure quality, dependability and professionalism. Its face 
value was established by experts in the field and it was subsequently pilot tested on a subset of participants. Apart from the determination of the CSFs relevant to TT, the Survey Instrument was also designed to determine the extent of KM readiness of SMEs in TT.

Senior Executives of 11 SMEs in the manufacturing and service industries that include food and beverage, technical services, clothing, oil and gas processing responded to the survey and the results were tabulated (Table $1 \&$ Table 2 ). In the Survey Instrument there were two parts (i \& ii) to each of the 21 questions. Part (i) of each question was developed to assist in determining the extent of KM/QM readiness of SMEs in TT while part (ii) helped to determine the CSFs for KM/QM implementation in SMEs in TT. The Likert-type scale approach was used to rate the level of agreement of responders on four points: strongly agree, agree, disagree, and strongly disagree, for each of the questions on the survey. The data was tabulated, analyzed, and depicted on graphs (Figure $2 \&$ Figure 3). The results pertaining to the extent of KM/QM readiness of SMEs in TT shown in Table 1, graphically represented in Figure 4 and further analyzed in Table 3, reflect the results obtained for part (i) of the survey questions. The results demonstrate that on average about $70 \%$ of the respondents strongly agree/agree that their organization has a QMS in place and that there is senior management commitment. An $87 \%$ of respondents strongly agree/agree that technical infrastructure, information systems, networking capabilities and human resource support for training and personal development are in place. However, only 54\% strongly agree/agree that knowledge distribution, application as well as knowledge creation and storage happen in their organization. Approximately 55\% strongly agree/agree that new product development,

Table 1. The Results of Responses Pertaining to the Extent of KM/QM Readiness of SMEs in TT.

\begin{tabular}{|c|c|c|c|c|c|}
\hline Question & Strongly Agree (\%) & Agree (\%) & Disagree (\%) & $\begin{array}{c}\text { Strongly } \\
\text { Disagree } \\
\text { (\%) }\end{array}$ & TOTAL \\
\hline Q1(i) & $0 \%$ & $91 \%$ & $9 \%$ & $0 \%$ & $100 \%$ \\
\hline Q2(i) & $18 \%$ & $55 \%$ & $27 \%$ & $0 \%$ & $100 \%$ \\
\hline Q3(i) & $0 \%$ & $64 \%$ & $18 \%$ & $18 \%$ & $100 \%$ \\
\hline Q4(i) & $0 \%$ & $82 \%$ & $18 \%$ & $0 \%$ & $100 \%$ \\
\hline Q5(i) & $0 \%$ & $73 \%$ & $27 \%$ & $0 \%$ & $100 \%$ \\
\hline Q6(i) & $0 \%$ & $82 \%$ & $18 \%$ & $0 \%$ & $100 \%$ \\
\hline Q7(i) & $9 \%$ & $91 \%$ & $0 \%$ & $0 \%$ & $100 \%$ \\
\hline Q8(i) & $0 \%$ & $91 \%$ & $9 \%$ & $0 \%$ & $100 \%$ \\
\hline Q9(i) & $0 \%$ & $82 \%$ & $18 \%$ & $0 \%$ & $100 \%$ \\
\hline Q10(i) & $0 \%$ & $91 \%$ & $9 \%$ & $0 \%$ & $100 \%$ \\
\hline Q11(i) & $0 \%$ & $82 \%$ & $18 \%$ & $0 \%$ & $100 \%$ \\
\hline Q12(i) & $0 \%$ & $73 \%$ & $27 \%$ & $0 \%$ & $100 \%$ \\
\hline Q13(i) & $0 \%$ & $55 \%$ & $45 \%$ & $0 \%$ & $100 \%$ \\
\hline Q14(i) & $0 \%$ & $82 \%$ & $18 \%$ & $0 \%$ & $100 \%$ \\
\hline Q15(i) & $0 \%$ & $36 \%$ & $64 \%$ & $0 \%$ & $100 \%$ \\
\hline Q16(i) & $0 \%$ & $9 \%$ & $91 \%$ & $0 \%$ & $100 \%$ \\
\hline Q17(i) & $0 \%$ & $55 \%$ & $45 \%$ & $0 \%$ & $100 \%$ \\
\hline Q18(i) & $0 \%$ & $91 \%$ & $9 \%$ & $0 \%$ & $100 \%$ \\
\hline Q19(i) & $0 \%$ & $18 \%$ & $82 \%$ & $0 \%$ & $100 \%$ \\
\hline Q20(i) & $9 \%$ & $91 \%$ & $0 \%$ & $0 \%$ & $100 \%$ \\
\hline Q21(i) & $0 \%$ & $18 \%$ & $82 \%$ & & \\
\hline & & & & $\%$ & $\%$ \\
\hline
\end{tabular}




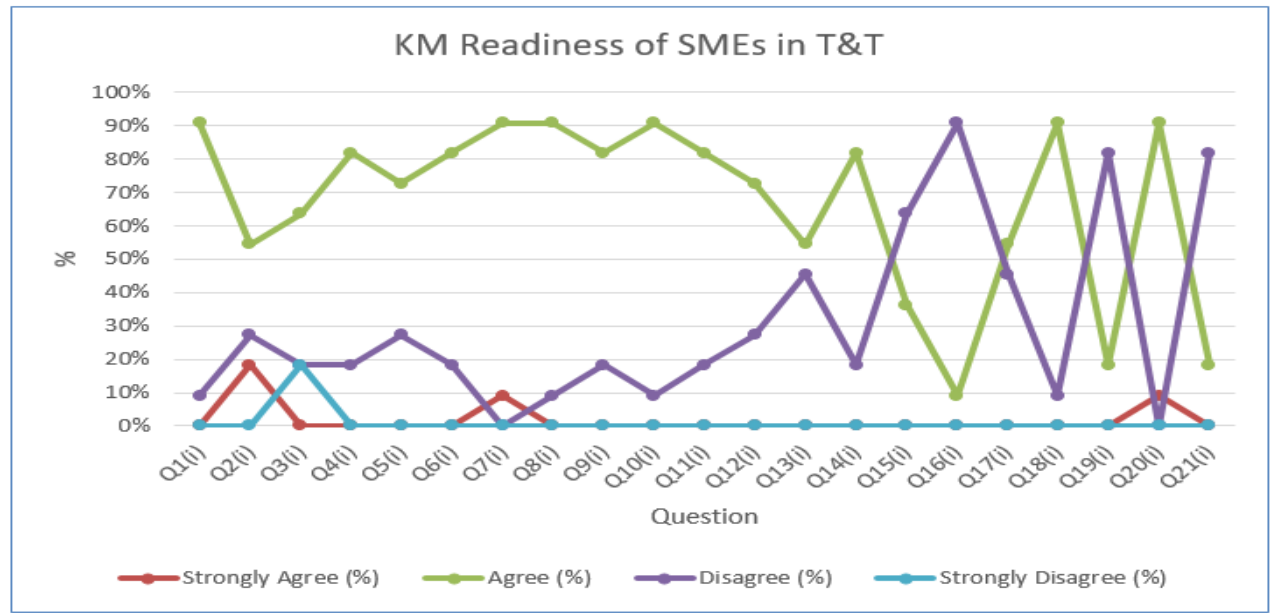

Figure 2. Graphical representation of responses pertaining to the extent of KM/QM readiness of SMEs in TT

$\mathrm{R} \& \mathrm{D} /$ innovation or knowledge acquisition takes place in their organization, just $36 \%$ strongly agree/agree that there is any knowledge measurement and only $9 \%$ strongly agree/agree that there is reward/recognition for knowledge related work. Also, a 45\% of respondents agree that help from external consultants will be needed to implement a KMS, with the majority indicating that sufficient expertise resides in-house. A $100 \%$ of respondents strongly agree that policies and procedures are needed to deal with current and future pandemics.

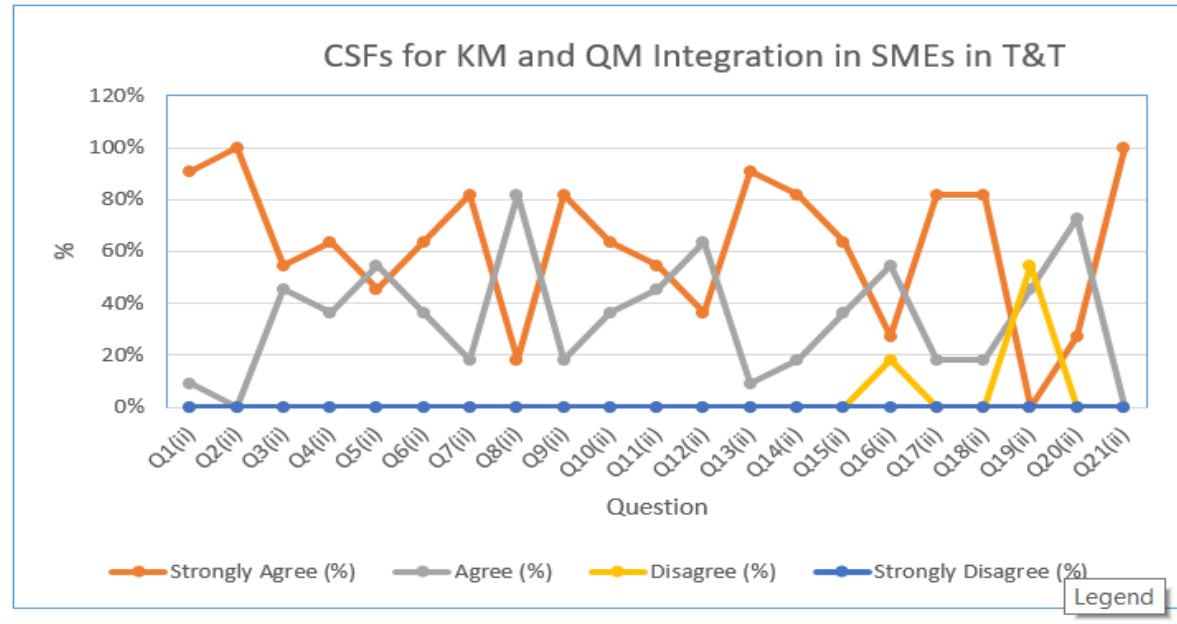

Figure 3. Graphical representation of the results concerning the identification of the relevant and indigenous CSFs for KM and QM integration for SMEs in TT

These results showed that although KM maturity may be somewhat lacking in SMEs in TT, many organizations are in a state of readiness for KM/QM integration as many SMEs already have a QMS in place, a fair degree of information systems and technical infrastructure, human resource support and most importantly, senior management commitment. To a lesser extent SMEs also appear to have a culture of trust and sharing. Identified deficiencies are knowledge strategy linking 
Table 2. The Results Concerning the Identification of the Relevant and Indigenous CSFs for KM and QM Integration for SMEs in TT.

\begin{tabular}{|c|c|c|c|c|c|}
\hline Questions & Strongly Agree (\%) & Agree (\%) & Disagree (\%) & Strongly Disagree (\%) & TOTAL \\
\hline Q1(ii) & $91 \%$ & $9 \%$ & $0 \%$ & $0 \%$ & $0 \%$ \\
\hline Q2(ii) & $100 \%$ & $0 \%$ & $0 \%$ & $0 \%$ & $100 \%$ \\
\hline Q3(ii) & $55 \%$ & $45 \%$ & $0 \%$ & $0 \%$ & $100 \%$ \\
\hline Q4(ii) & $64 \%$ & $36 \%$ & $0 \%$ & $0 \%$ & $100 \%$ \\
\hline Q5(ii) & $45 \%$ & $55 \%$ & $0 \%$ & $0 \%$ & $100 \%$ \\
\hline Q6(ii) & $64 \%$ & $36 \%$ & $0 \%$ & $0 \%$ & $100 \%$ \\
\hline Q7(ii) & $82 \%$ & $18 \%$ & $0 \%$ & $0 \%$ & $100 \%$ \\
\hline Q8(ii) & $18 \%$ & $82 \%$ & $0 \%$ & $0 \%$ & $100 \%$ \\
\hline Q9(ii) & $82 \%$ & $18 \%$ & $0 \%$ & $0 \%$ & $100 \%$ \\
\hline Q10(ii) & $64 \%$ & $36 \%$ & $0 \%$ & $0 \%$ & $100 \%$ \\
\hline Q11(ii) & $55 \%$ & $45 \%$ & $0 \%$ & $0 \%$ & $100 \%$ \\
\hline Q12(ii) & $36 \%$ & $64 \%$ & $0 \%$ & $0 \%$ & $100 \%$ \\
\hline Q13(ii) & $91 \%$ & $9 \%$ & $0 \%$ & $0 \%$ & $100 \%$ \\
\hline Q14(ii) & $82 \%$ & $18 \%$ & $0 \%$ & $0 \%$ & $100 \%$ \\
\hline Q15(ii) & $64 \%$ & $36 \%$ & $0 \%$ & $0 \%$ & $100 \%$ \\
\hline Q16(ii) & $27 \%$ & $55 \%$ & $18 \%$ & $0 \%$ & $100 \%$ \\
\hline Q17(ii) & $82 \%$ & $18 \%$ & $0 \%$ & $0 \%$ & $100 \%$ \\
\hline Q18(ii) & $82 \%$ & $18 \%$ & $0 \%$ & $0 \%$ & $100 \%$ \\
\hline Q19(ii) & $0 \%$ & $45 \%$ & $55 \%$ & $0 \%$ & $0 \%$ \\
\hline Q20(ii) & $27 \%$ & $0 \%$ & $0 \%$ & $0 \%$ & \\
\hline Q21(ii) & $100 \%$ & $0 \%$ & $0 \%$ & $10 \%$ \\
\hline
\end{tabular}

to business strategy, knowledge creation, storage, distribution, application, and measurement as well as reward and recognition for knowledge related work. The results concerning the identification of the relevant and indigenous CSFs for KM and QM integration for SMEs in TT associated with part (ii) of the survey questions are shown in Table 2 and Figure 3 and further analyzed in Table 4 . The results showed that $100 \%$ of the respondents strongly agree/agree that having a QMS in place can aid in the development of a KMS. This statistic was obtained from responses to question 1(ii) and question 18(ii) (Appendix 1). The identified CSFs for KM implementation suggested by senior executives were consistent with those found by (BissoonMaharaj \& Pun, 2010). A 100\% of the respondents strongly agree/agree to part (ii) of questions 2 , 3, 4, 9, 10 and 21 (Table 4), indicating that there is consensus that KM Planning and Review is a CSF and includes elements of commitment from top management, knowledge strategy linked to business strategy, policies and procedures, coordination, monitoring and control, clear objectives, and motivation. All (100\%) respondents strongly agree/agree with part (ii) of questions 1, 5, 6, 7, 8, 18 and 20 (Table 4) indicating that Infrastructure Building is a CSF for KM/QM integration in SMEs in TT. Supporting this CSF were the respondents' agreement to having a QMS in place, well developed information technology to include networking, information systems, technical infrastructure, a culture of sharing and trust, facilitation of training and learning, good Customer/Supplier relations, and well managed document, data, and quality records systems. Additionally, all (100\%) respondents strongly agree/agree with part (ii) of questions 11, 12, 13 and 14 (Table 4) identifying Knowledge Process Implementation to be a CSF. The respondents' agreement that knowledge creation, storage processes, distribution, and application to being essential for KM implementation, supported this CSF. 
Table 3. Analysis of Results to Determine Readiness of SMEs in TT for KM/QM Integration.

\begin{tabular}{|c|c|c|}
\hline $\begin{array}{l}\text { Question Number/s } \\
\text { (part i) }\end{array}$ & $\begin{array}{l}\% \text { Responses to } \\
\text { Strongly Agree/ Agree }\end{array}$ & Conclusion \\
\hline $2,4,9,10,21$ & $72 ; 82 ; 82 ; 91 ; 18$ & QMS in place and senior management commitment \\
\hline $1,5,6,7,8,18,20$ & $91 ; 73 ; 82 ; 91 ; 91 ; 91 ; 91$ & $\begin{array}{l}\text { Infrastructure in place: technical infrastructure, information systems, } \\
\text { networking capabilities. human resource support for training }\end{array}$ \\
\hline $3,11,12,13,14,15$ & $64 ; 60 ; 73 ; 55 ; 55 ; 20$ & $\begin{array}{l}\text { Knowledge creation; storage; distribution; application and } \\
\text { measurement are lacking }\end{array}$ \\
\hline 17 & 55 & $\begin{array}{l}\text { R\&D/Innovation; new product development and knowledge } \\
\text { acquisition lacking }\end{array}$ \\
\hline 15 & 36 & Little Knowledge measurement and Improvement \\
\hline 16 & 9 & Reward/recognition for knowledge related work is lacking \\
\hline 19 & 18 & $\mathrm{n} / \mathrm{a}$ \\
\hline
\end{tabular}

Measurement and Improvement was also identified to be CSFs for KM Implementation, with $100 \%$ respondents strongly agree/agree to question 15(ii) (Table 4). In addition, Innovation and Reward and Recognition were also deemed important for KM success in SMEs in TT. Furthermore, it seemed clear that SMEs in TT believe that they are equipped to develop their own KMS without the assistance of external consultants, as can be seen from the response to Question 19(ii) (Table 4), with only $45 \%$ of the respondents strongly agree/agree that help from external consultants will be necessary for successful implementation of KMS.

Table 4. Analysis of Results to Determine CSFs for KM/QM Integration in SMEs in TT

\begin{tabular}{|l|l|l|}
\hline Question Number/s (part ii) & $\begin{array}{l}\text { \% Responses to } \\
\text { Strongly Agree/Agree }\end{array}$ & CSF \\
\hline $2,3,4,9,10,21$ & 100 & $\begin{array}{l}\text { KM Planning and Review: top management commitment, } \\
\text { knowledge strategy linking to business strategy, policies and } \\
\text { procedures, clear objectives }\end{array}$ \\
\hline $1,5,6,7,8,18,20$ & 100 & $\begin{array}{l}\text { Infrastructure Building: IT -networking, information systems, } \\
\text { technical infrastructure, culture of sharing and trust, facilitation } \\
\text { of training and learning, good Customer/Supplier relations, well } \\
\text { managed document, data and quality records systems }\end{array}$ \\
\hline $11,12,13,14$ & 100 & $\begin{array}{l}\text { Knowledge Process Implementation: creation, storage } \\
\text { processes, distribution and application }\end{array}$ \\
\hline 17 & 100 & Innovation \\
\hline 15 & 100 & Measurement and Improvement \\
\hline 16 & 82 & Reward, Recognition \\
\hline 19 & 45 & n/a \\
\hline
\end{tabular}

\section{A KMS Introduction Model for KM/QM Integration in SMEs in TT}

A KMS Introduction Model for SMEs in TT is proposed in this study and a schematic representation is depicted in Figure 6. The KM model proposed was formulated from the results of the survey of eleven senior executives of SMEs in TT, where indigenous and relevant CSFs for implementation of a KM system were identified (Table 4). The survey instrument was developed 
through identification of existing CSFs for KM and QM implementation, identified from literature review. The survey was validated to ensure quality, dependability, and professionalism. Its face value was established by experts in the field and it was subsequently pilot tested on a subset of participants. Most of the companies surveyed already had a QMS in place, which has many common characteristics with KM including senior management commitment, vision statement and review, document control, training, process management, measurement, customer/supplier relationship, corrective, and preventive action. Based on analysis of the survey results to determine the CSFs for KM/QM integration in SMES in TT (Table 4), five phases are being proposed: KM Planning and Review, Infrastructure Building, Knowledge Process Implementation, Innovation and Measurement, Improvement, Reward and Recognition.

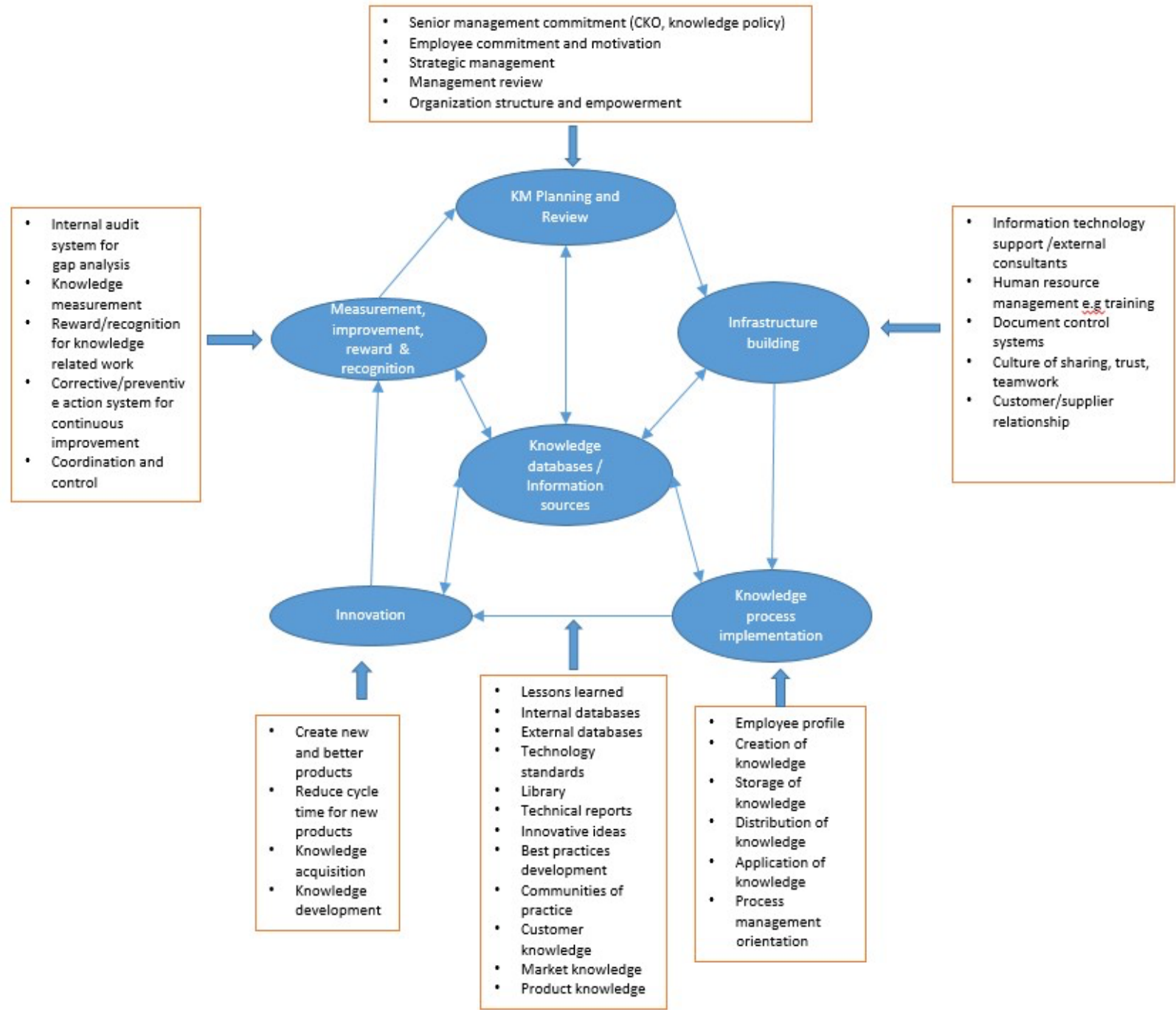

Figure 4. A proposed KMS Introduction Model for KM/QM Integration in SMEs in TT (Modified from Tan \& Hung, 2006)

Phase one of the model is KM Planning and Review. In this phase senior management needs to demonstrate commitment and support through appointment of a Chief Knowledge Officer (CKO), development of knowledge policy/objectives, management reviews and involvement of all employees with responsibilities and authorities clearly defined. The second phase is Infrastructure 
Building which was also proposed by Meso and Smith (2000) and geared towards building infrastructure, bearing in mind that people are the core of a KMS and that there must be systems for acquisition, conversion, application and protection of knowledge and proper KM. According to Bissoon-Maharaj and Pun (2010), KM facilitates the acquisition, application, and integration of knowledge from both inside and outside of the organization.

Phase three is Knowledge Process Implementation and according to the executives surveyed, knowledge creation, storage, distribution, and application must be facilitated. This requirement was also suggested by Nonaka, (1994) who indicated that organizations play a critical role in expressing and communicating new tacit or explicit knowledge developed by persons within the organization. Additionally, according to Bissoon-Maharaj and Pun (2010), organizational memory comprises knowledge existing in several forms, for example written documentation, electronic databases, expert systems, documented procedures and processes and tacit knowledge gained by individuals and networks of individuals. According to Fugate et al. (2009) and Garcia-Morales et al. (2006) knowledge distribution to locations where it is needed and can be used, is necessary. However, this is not a simple process since organizations are often not aware of the knowledge that resides within the organization and have weak systems for locating and retrieving this knowledge.

Gupta and Govindarajan (2000) have conceptualized knowledge distribution/transfer the organization's ability to realise the value of knowledge, trust the source of that knowledge and apply it to improve business performance. Also, application of knowledge is important. Grant (1996) identified that for the integration of knowledge to create organization capability, three primary areas are needed. These include directives, organizational routines, and self-contained task teams. He suggests that these rules, standards, procedures, and instructions must be developed to convert tacit knowledge to explicit integrated knowledge. Innovation is suggested as the fourth phase and is seen as being necessary to facilitate new knowledge for a successful KM and QM integration in SMEs in TT. Abou-Zeid and Cheng (2004) indicated that to benefit the most from organizational knowledge resources, it is necessary to in-cooperate KM and innovation. Jang et al. (2002) in their case study of Samsung SDI showed that in the real-world KM is heavily associated with process innovation. Measurement, Improvement, Reward and Recognition systems, is the fifth phase. As explained by Bissoon-Maharaj and Pun, (2010), this phase provides means to gauge performance and provide feedback. Underutilized resources, repurposing of resources, different procedures, new products and services can become a catalyst to generate economic growth. Also, reward and incentives systems must correspond with management systems used to measure performance, this will facilitate KM/QM integration (Bissoon-Maharaj \& Pun, 2010).

\section{Conclusion}

The results of a survey administered to senior management personnel from SMEs in TT identified the CSFs for QM and KM. The results showed that the SMEs in TT demonstrate insignificant KM maturity outside of their experience with existing QMS but are generally in a state of readiness for $\mathrm{KM} / \mathrm{QM}$ integration due to existing QMS, information systems and technical infrastructure, human resource support and most importantly, senior management commitment. A KM/QM integration model is proposed outlining five phases: KM Planning and Review, Infrastructure Building, Knowledge Process Implementation, Innovation and Measurement, Improvement, Reward and Recognition. The proposed strategy of integration of QM and KM will aid organizations' 
competitiveness and efficiency, enhance business growth, and increase profits. Senior executives of SMEs and other businesses can apply the results of this research to help develop strategies to integrate QM and KM and enhance business capabilities. Future work will involve increasing the span of the survey to include more respondents and also validating the model and findings of this paper.

\section{References}

Abou-Zeid, E.-S., \& Cheng, Q. (2004). The effectiveness of innovation: A knowledge management approach. International Journal of Innovation Management, 8(3), 261-274. https://doi.org/10.1142/S1363919604001052

Barnes, S., \& Milton, N. (2014). Designing a successful KM strategy: A guide for the knowledge management professional. Information Today, Inc.

Bissoon-Maharaj, S., \& Pun, K. F. (2010). IEM-008: Integrating knowledge management with quality management practices in SMEs in Trinidad: A review and research agenda.

Proceedings of the 2nd Industrial Engineering and Management Conference, St. Augustine, Trinidad and Tobago: University of the West Indies, 46 - 53.

Choo, A. S., Linderman, K. W., \& Schroeder, R. G. (2007). Method and context perspectives on learning and knowledge creation in quality management. Journal of Operations Management, 25(4), 918-931.

Desouza, K. C., \& Awazu, Y. (2006). Knowledge management at SMEs: Five peculiarities. Journal of Knowledge Management, 10(1), 32-43. https://doi.org/10.1108/ 13673270610650085

Fugate, B. S., Stank, T. P., \& Mentzer, J. T. (2009). Linking improved knowledge management to operational and organizational performance. Journal of Operations Management, 27(3), 247-264. https://doi.org/10.1016/j.jom.2008.09.003

Garcia -Morales, V. J., LLorens-Montes, F. J., \& Verdu-Jover, A. j. (2006). Organisational learning categories: Their influence on organisational performance. International Journal of Innovation and Learning, 3(5), 518-536. https://doi.org/10.1504/IJIL.2006.010487

Garstenauer, A., Blackburn, T., \& Olson, B. (2014). A knowledge management based approach to quality management for large manufacturing organizations. Engineering Management Journal, 26(4), 47-58. https://doi.org/10.1080/10429247.2014.11432028

Grant, R. M. (1996). Toward a knowledge-based theory of the firm. Strategic Management Journal, 17(S2), 109-122. https://doi.org/10.1002/smj.4250171110

Gupta, A., \& Govindarajan, V. (2000). Knowledge flows within multinational corporations. Strategic Management Journal, 21(4), 473-496.

Harris, M. (2000, August). The current situation of small and medium-sized industrial enterprises in Trinidad and Tobago, Barbados and St. Lucia.

Jang, S., Hong, K., Bock, G.-W., \& Kim, I. (2002). Knowledge management and process innovation: The knowledge transformation path in Samsung SDI. Journal of Knowledge Management, 6(5), 479-485. https://doi.org/10.1108/13673270210450582 
Karimzadegan, D., Tanha, J., \& Majd, E. (2011). Providing a comprehensive knowledge management model. Journal of Research in International Business and Management, 1(6), 155-163.

Koenig, M. E. (2018, January 15). Stay up-to-date on everything KM - Subscribe to KMWorld NewsLinks and more today. https://www.kmworld.com/About/What is Knowledge Management

Kohl, H., Orth, R., \& Steinhofel, E. (2015). A practical approach to process-oriented knowledge management. The Electronic Journal of Knowledge Management, 13(1), 74-87.

Lari, A. (2002). An integrated information system for quality management. Business Process Management Journal, 8(2), 169-182. https://doi.org/10.1108/14637150210425126

Lee, C.-L., Ho, C. T., \& Chiu, Y. L. (2008). The impact of knowledge management enablers on non-financial performance in small and medium enterprises. International Journal of Technology Management, 43(1/2/3), 266-283. https://doi.org/10.1504/IJTM.2008.019419

Lim, D., \& Klobas, J. (2000). Knowledge management in small enterprises. The Electronic Library, 18(6), 420-433. https://doi.org/10.1108/02640470010361178

Lin, C., \& Wu, C. (2005). Managing knowledge contributed by ISO 9001:2000. International Journal of Quality \& Reliability Management, 22(9), 968-985. https://doi.org/10.1108/02656710510625239

Linderman, K., Schroeder, R. G., Zaheer, S., Liedtke, S., \& Choo, A. S. (2004). Integrating quality management practices with knowledge creation processes. Journal of Operations Management, 22(6), 589-607. https://doi.org/10.1016/j.jom.2004.07.001

Mazzarol, T. (2014). Research review: A review of the latest research in the field of small business and entrepreneurship. Financial Management in SMEs, 21(1), 2-13. https://doi.org/10.1080/13215906.2014.11082073

Meso, P., \& Smith, R. (2000). A resource-based view of organizational knowledge management systems. Journal of Knowledge Management, 4(3), 224-234. https://doi.org/10.1108/ 13673270010350020

Nonaka, I. (1994). A dynamic theory of organizational knowledge creation. Organization Science, 5(1), 14-37.

Organization for Economic Co-operation \& Development (2021, May 10). OECD policy responses to coronavirus (COVID-19): The territorial impact of COVID-19: Managing the crisis and recovery across levels of government. https://www.oecd.org/coronavirus/policyresponses/the-territorial-impact-of-covid-19-managing-the-crisis-and-recovery-acrosslevels-of-government-a2c6abaf/

Ribiere, V. M., \& Khorramshahgol, R. (2004). Integrating total quality management and knowledge management. Journal of Management Systems, 16(1), 39-54.

Rincon, M., \& Orero, A. (2004). Knowledge management in developing countries: Understanding an interpretivist approach. Proceedings of the 10th Americas Conference on Information Systems, New York, NY, 501-508. https://aisel.aisnet.org/amcis2004/72 
Ramkissoon, S., Alexamder, D., Maharaj, R., \& Mohammed, S. (2020). Evaluation of a low salinity water flooding with polymer gel treatment in Trinidad and Tobago. Journal of Petroleum Exploration and Production Technology, 10(1007), 3971-3981.

Rothwell, P., \& Zegveld, W. (1981). Innovation and the small and medium sized firm: Their role in employment and in economic change. Springer.

Teece, D. J. (1998). Capturing value from knowledge assets: The new economy, markets for know-how, and intangible assets. California Management Review, 40, 55-79. https://doi.org/10.2307/41165943

The Government of Trinidad and Tobago (2021a). Oil and gas Industry: Overview. Ministry of Energy and Energy Industries. https://www.energy.gov.tt/our-business/oil-and-gasindustry/

The Government of Trinidad and Tobago. (2021b). Statistics of Trinidad and Tobago Business Establishments. Central Statistical Office. https://cso.gov.tt/subjects/business-and-industry$\underline{21}$

The Government of Trinidad and Tobago. (2021c). Vision 2030. Ministry of Planning and Development. https://www.planning.gov.tt/content/vision-2030

The World Bank Global Economic Prospect (2020, June 8). COVID-19 to plunge global economy into worst recession since World War II. https://www.worldbank.org/ en/news/press-release/2020/06/08/covid-19-to-plunge-global-economy-into-worstrecession-since-world-war-ii

\section{Authors' Biographies}

Sandra Bissoon-Maharaj, MSc, BSc, holds a Bachelors (BSc) Degree in Industrial Engineering and a Masters (MSc) Degree in Production Engineering and Management. She is currently a Senior Instructor at the University of Trinidad \& Tobago (UTT) in the Process Engineering Program where she lectures in Engineering Mathematics and Statistics, Quality and HSE Engineering and Process Analysis and Optimization courses. She worked in industry for thirteen years as Industrial \& Production Engineering Consultant, Project Engineer, Quality, Health, Safety and Environment Manager and Senior

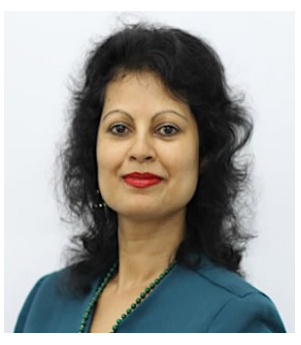
Marketing Manager. She was involved in developing, documenting and implementing QMS to ISO9002 standard in two organizations, one in Trinidad and the other in Guyana. Both of these organizations achieved ISO9002 certification.

Rean Maharaj, PhD, MPhil, BSc, holds a Bachelors (B.Sc.) Degree in Chemistry specializing in Analytical Chemistry, a Masters of Philosophy (M.Phil.) degree in the area of Material Science and a Ph.D. in Process and Utilities Engineering. After a very successful career in industry, Dr. Maharaj served as Analyst at the Trinidad and Tobago Forensic Science Centre (Chemistry Department) for eight years. He joined academia in 2006 and currently holds the position of Associate Professor and serves as Program Leader in the Process Engineering Program at the University of Trinidad and Tobago

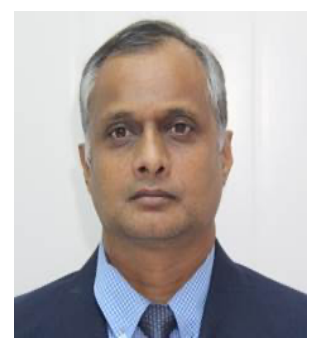
where he lectures in Chemistry, Thermodynamics and Material Science based courses. He has an 
active research agenda focusing on waste management and sustainable and renewable energy systems as evidenced by his numerous scientific publications and projects. 


\section{APPENDIX 1: SURVEY FOR ACADEMIC RESEARCH}

Purpose: Survey to determine the extent of and Critical Success Factors (CSFs) for Knowledge Management System (KMS) and Quality Management System (QMS) in Small and Medium Enterprises (SMEs) in Trinidad \& Tobago.

Details: KM helps organizations to identify, select, organize, disseminate and transfer important information to ensure that these are available in the right place at the right time to enable informed decisions. It also helps to improve efficiency by reducing the need to rediscover knowledge. The questions in this survey were derived from literature review and highlight factors that influence the successful implementation of KMS and QMS. Within recent times, even pre-Covid-19 pandemic, Trinidad has been experiencing a downturn in economic activity. Organizations more so now than ever, need to implement techniques to achieve that competitive edge - so necessary for survival.

The survey should take about 20 minutes to complete. Your information will be treated with the strictest confidentiality and will be used solely for academic research purposes.

Name of Company (optional):

Type of Company (e.g. Manufacturing, Food, Service):

Size of Company: Micro (5 to 9 employees) $\square \quad$ Small (10 to 49 employees) $\square$

Medium (50 to 250 employees) $\square \quad$ Large (250 or more employees)

Your Name(optional): Click or tap here to enter text.

Position in Company: Click or tap here to enter text.

As a member of Management in your Organization, please indicate if you Strongly Agree (4 points); Agree (3); Disagree (2) or Strongly Disagree (1) with the following questions. Please also feel free to comment further.

1. i) Does your organization have a Quality Management System in place? If yes, please state for how long and type of system (e.g. ISO9002 QMS)

Strongly Agree: $\square \quad$ Agree: $\square \quad$ Disagree:

Strongly Disagree:

ii) Do you think having a QMS in place can aid in the implementation of a KMS?

Strongly Agree: $\square \quad$ Agree: $\square \quad$ Disagree: $\square \quad$ Strongly Disagree:

Please Comment:

2. i) Is there commitment and support from top management for new initiatives?

Strongly Agree: $\square \quad$ Agree: $\square \quad$ Disagree: $\square$ Strongly Disagree:

ii) Is commitment and support from top management necessary for a company trying to implement a KMS?

Strongly Agree: $\square \quad$ Agree: $\square \quad$ Disagree: $\square \quad$ Strongly Disagree:

Please Comment:

3. i) Is there knowledge strategy linking to business strategy at your Organization?

Strongly Agree: $\square \quad$ Agree: $\square \quad$ Disagree: $\square \quad$ Strongly Disagree:

ii) Is it important to have knowledge strategy linking to business strategy at your Organization?

Strongly Agree: $\square \quad$ Agree: $\square \quad$ Disagree: $\square \quad$ Strongly Disagree:

Please Comment:

4. i) Are there motivation initiatives and clear objectives in your Organization?
Strongly Agree:
Agree:
Disagree:
Strongly Disagree:

ii) Is it important to have motivation initiatives and clear objectives for implementation of a KMS?

Strongly Agree: $\square \quad$ Agree: $\square \quad$ Disagree: $\square \quad$ Strongly Disagree:

Please Comment:

5. i) Is there a culture of sharing, trust, friendliness and nurturing at your Organization?
Strongly Agree:
Agree:
Disagree:
Strongly Disagree:

ii) Is it important to have a culture of sharing, trust, friendliness and nurturing for implementation of a KMS?

Strongly Agree: $\square \quad$ Agree: $\square \quad \square \quad$ Disagree: $\square$ Strongly Disagree:

Please Comment:

6. i) Is there well developed information technology, such as networking, information systems and technical infrastructure in your Organization?

Strongly Agree: $\square \quad$ Agree: $\square \quad$ Disagree: $\square \quad$ Strongly Disagree:

ii) Is it important to have well developed information technology, such as networking, information systems and technical infrastructure for implementation of a KMS? 
Strongly Agree:

Please Comment:

7. i) Is there human

Strongly Agree:

Strongly Agree:

Please Comment:

8. i) Does your Company support and recognize independent studies pursued by employees that are in line with the Company's business?

Strongly Agree: $\square$

Agree:

Disagree:

Strongly Disagree:

ii) Do you think that independent studies pursued by employees that are in line with the Company's business, will be beneficial to a KMS?
Strongly Agree:
Agree:
Disagree:
Strongly Disagree:

Please Comment:

9. i) Is there organization context, such as organization structure, empowerment and leadership in your Organization?
Strongly Agree:
Agree:
Disagree:
Strongly Disagree:

ii) Is it important to have organization context, such as organization structure, empowerment and leadership for implementation of a KMS?
Strongly Agree:
Agree:
Disagree:
Strongly Disagree:

Please Comment:

10. i) Are there managerial support processes such as coordination and control in your Organization?
Strongly Agree:
Agree:
Disagree:
Strongly Disagree:

ii) Is it important to have managerial support processes such as coordination and control for implementation of a KMS?
Strongly Agree:
Agree:
Disagree:
Strongly Disagree:

Please Comment:

11. i) Is there a knowledge creation process in your Organization?
Strongly Agree:
Agree:
Disagree:
Strongly Disagree:

ii) Is it important to have knowledge creation process for successful implementation of a KMS?
Strongly Agree:
Agree:
Disagree:
Strongly Disagree:

Please Comment:

12. i) Is there knowledge storage process in your Organization?
Strongly Agree:
Agree:
Disagree:
Strongly Disagree:

ii) Is it important to have a knowledge storage process for successful implementation of a KMS?

Strongly Agree:

Agree:

Disagree:

Strongly Disagree:

Please Comment:

13. i) Is there knowledge distribution process in your Organization?
Strongly Agree:
Agree:
Disagree:
Strongly Disagree:

ii) Is it important to have a knowledge distribution process for successful implementation of a KMS?

Strongly Agree:

Agree:

Disagree:

Strongly Disagree:

Please Comment:

14. i) Is there knowledge application process in your Organization?

Strongly Agree: $\square \quad$ Agree: $\square \quad$ Disagree: $\square \quad$ Strongly Disagree:

ii) Is it important to have a knowledge application process for successful implementation of a KMS?

Strongly Agree: $\square \quad$ Agree: $\square \quad$ Disagree: $\square \quad$ Strongly Disagree:

Please Comment:

15. i) Is there knowledge measurement in your Organization?

Strongly Agree:

Agree:

Disagree:

Strongly Disagree:

ii) Is it important to have knowledge measurement for successful implementation of a KMS?
Strongly Agree:
Agree:
Disagree:
Strongly Disagree:

Please Comment:

16. i) Is there reward for knowledge related work in your Organization?
Strongly Agree:
Agree:
Disagree:
Strongly Disagree:

ii) Is it important to have reward for knowledge related work for successful implementation of a KMS?

Strongly Agree: $\square \quad$ Agree: $\square \quad$ Disagree: $\square \quad$ Strongly Disagree:

Please Comment:

17. i) Is your Company involved in $R \& D /$ innovation e.g. new product development and knowledge acquisition?
Strongly Agree:
Agree:
Disagree:
Strongly Disagree:

ii) Do you think innovation is important for successful implementation of a KMS? 
Strongly Agree:

Agree:

Disagree:

Strongly Disagree:

Please Comment:

18. i) Is there well-managed document and quality record control process in your Organization?
Strongly Agree:
Agree:
Disagree:
Strongly Disagree:

ii) Do you think that a well-managed document and quality record process will aid in the successful implementation of a KMS?
Strongly Agree:
Agree:
Disagree:
Strongly Disagree:

Please Comment:

19. i) Does your Organization get help from external experienced consultants?
Strongly Agree:
Agree:
Disagree:
Strongly Disagree:

ii) Do you think getting help from external experienced consultants will be necessary for successful implementation of a KMS?

Strongly Agree: $\square \quad$ Agree: $\square \quad$ Disagree: $\square \quad$ Strongly Disagree:

Please Comment:

20. i) Does your Company have good relationship with Customers/Suppliers?
Strongly Agree:
Agree:
Disagree:
Strongly Disagree:

ii) Do you think having good relationship with Customers/Suppliers can aid in the implementation of a successful KMS?
Strongly Agree:
Agree:
Disagree:
Strongly Disagree:

Please Comment:

21. i) Has your organization taken steps to document the experiences from the Covid-19 pandemic and develop policies and procedures to mitigate its impact?
Strongly Agree:
Agree:
Disagree:
Strongly Disagree:

ii) Do you think it is necessary to develop policies and procedures to deal with current and future pandemics?

Strongly Agree:

Agree:

Disagree:

Strongly Disagree:

Please Comment:

\section{THANK YOU FOR COMPLETING THIS SURVEY}

